\title{
Variations in runoff, sediment load and their relationship for a major sediment source area of the Jialing River basin, southern China
}

\author{
Yiting $\mathrm{Shao}^{1}$, Xingmin $\mathrm{Mu}^{2}$, Yi $\mathrm{He}^{3}$, and Kai Chen ${ }^{4}$ \\ ${ }^{1}$ Institute of Soil and Water Conservation Chinese Academy of Sciences and Ministry of \\ Water Resources \\ ${ }^{2}$ Institute of Soil and Water Conservation \\ ${ }^{3}$ College of Urban and Environmental Sciences, Northwest University \\ ${ }^{4}$ Hydrology and Water Resources Survey Bureau in Gansu Province
}

December 22, 2020

\begin{abstract}
Investigation of the variations in runoff and sediment load as well as their dynamic relation is conducive to understanding hydrological regimes changes and supporting channel regulation and fluvial management. This study was undertaken in the Xihanshui catchment, which is known for its high sediment-laden in the Jialing River of the Yangtze River basin, southern China, to evaluate the change characteristics of runoff, sediment load and their relationship at multi-temporal scales from 1966 to 2016. The results showed that the monthly runoff changed significantly for more months whereas the significant changes in monthly sediment load occurred from April to September. The contributions of runoff in summer and autumn and sediment load in summer to their annual value changes were greater. The annual runoff and sediment load in the Xihanshui catchment both exhibited significant decreasing trends $(\mathrm{P}<0.05)$ with significant mutation in $1993(\mathrm{P}<0.05)$. The average annual runoff in the change period (1994-2016) decreased by $49.60 \%$ and annual sediment load displayed a substantial decline with a reduction of $77.76 \%$ in comparison with the reference period (1966-1993). The variation of the relationship between runoff and sediment load in the catchment was time-dependent. The annual and extreme monthly runoff-sediment relationship could be generally expressed as power function, whereas the monthly runoff-sediment relationships were changeable. Spatially, the relationship between annual runoff and sediment load could be partly attributed to sediment load changes in the upstream and runoff variations in the downstream and it became weaker in the change period due to the impact of existing soil and water conservation measures. Quantitative assessment showed that human activity played a dominant role in annual runoff and sediment load reduction, with the contributions of $67.07 \%$ and $87.64 \%$, respectively.
\end{abstract}

\section{Hosted file}

Manuscript.pdf available at https://authorea.com/users/384348/articles/499997-variationsin-runoff-sediment-load-and-their-relationship-for-a-major-sediment-source-area-of-thejialing-river-basin-southern-china

\section{Hosted file}

Tables.pdf available at https://authorea.com/users/384348/articles/499997-variations-inrunoff-sediment-load-and-their-relationship-for-a-major-sediment-source-area-of-thejialing-river-basin-southern-china 

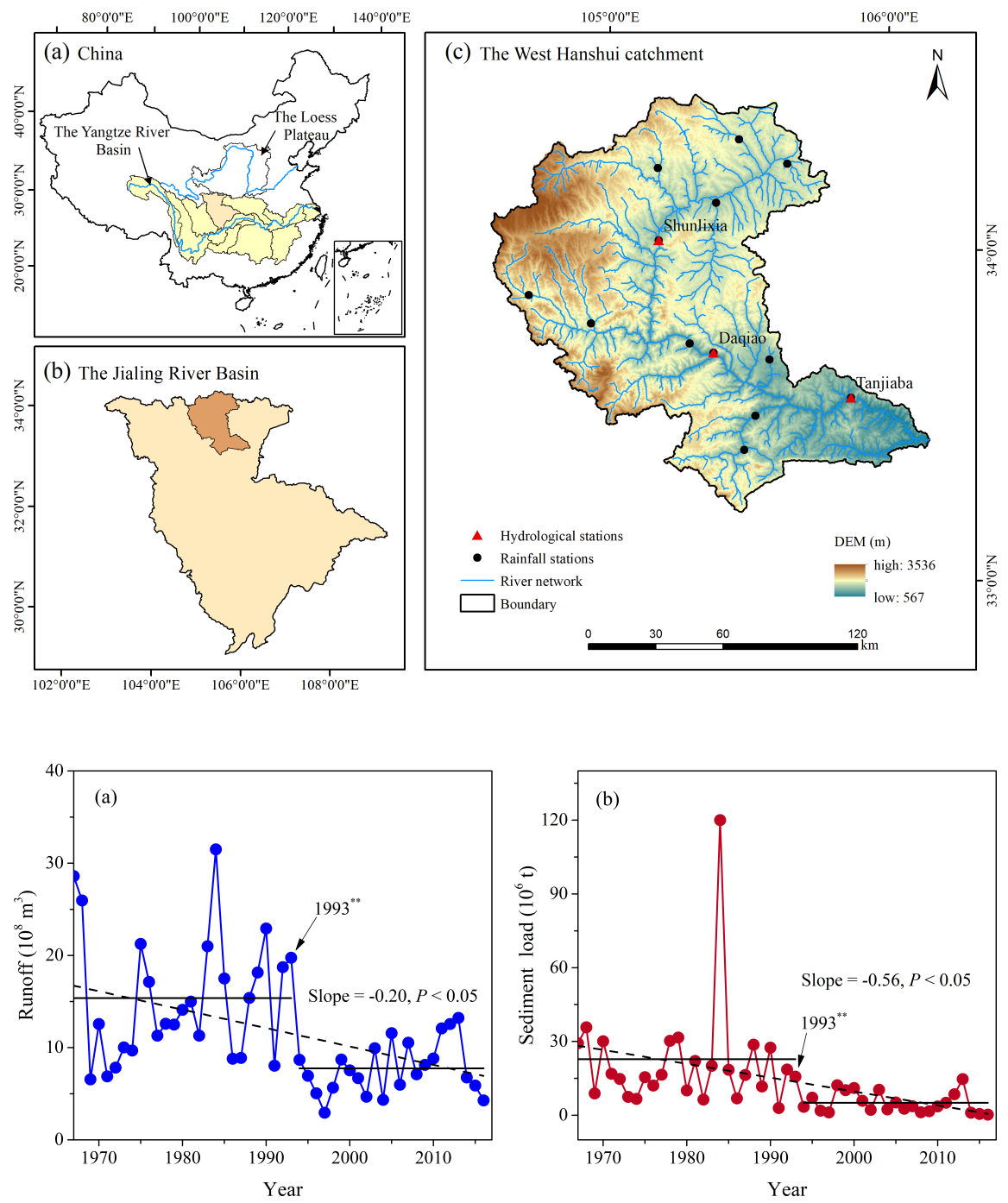

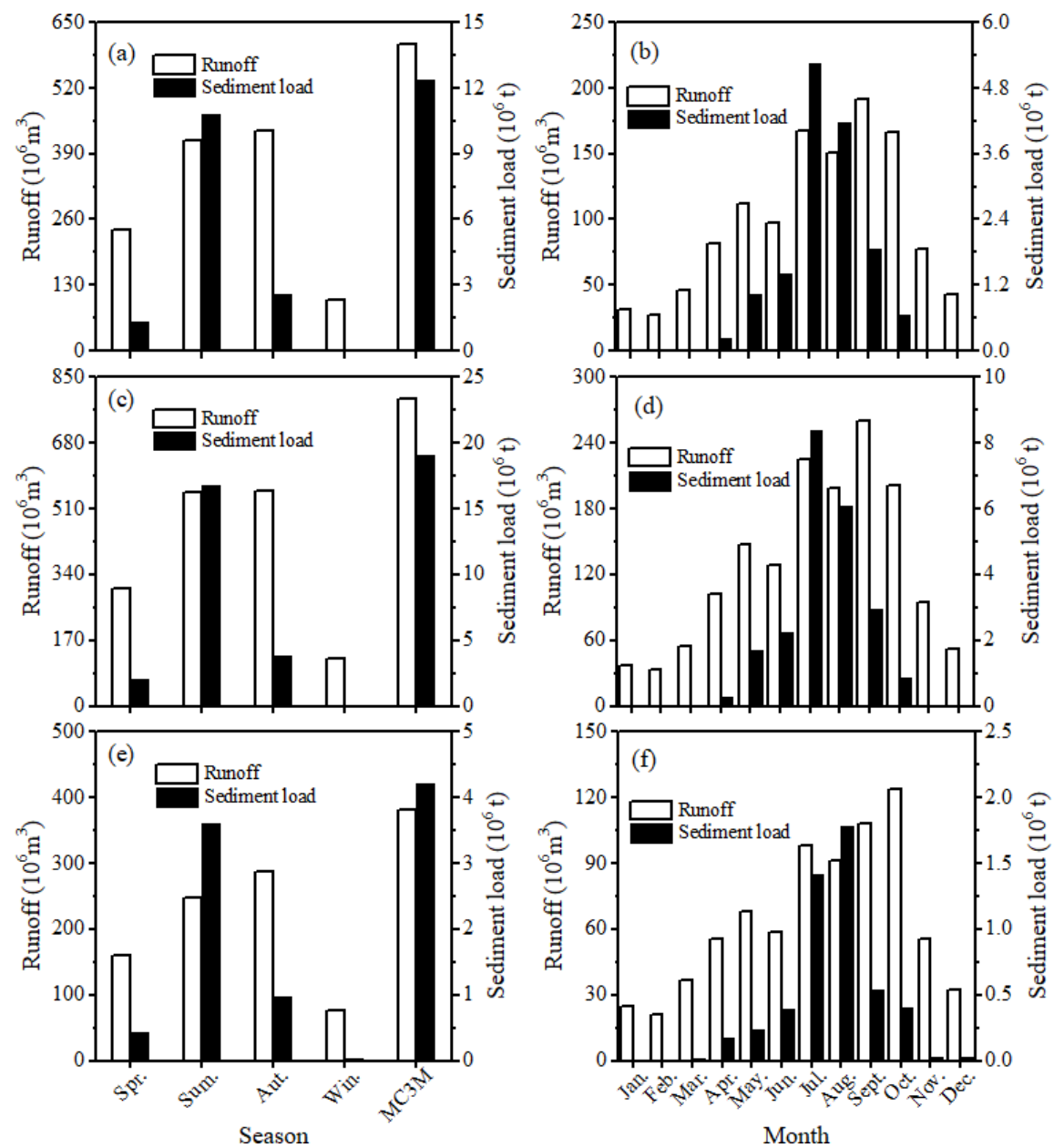


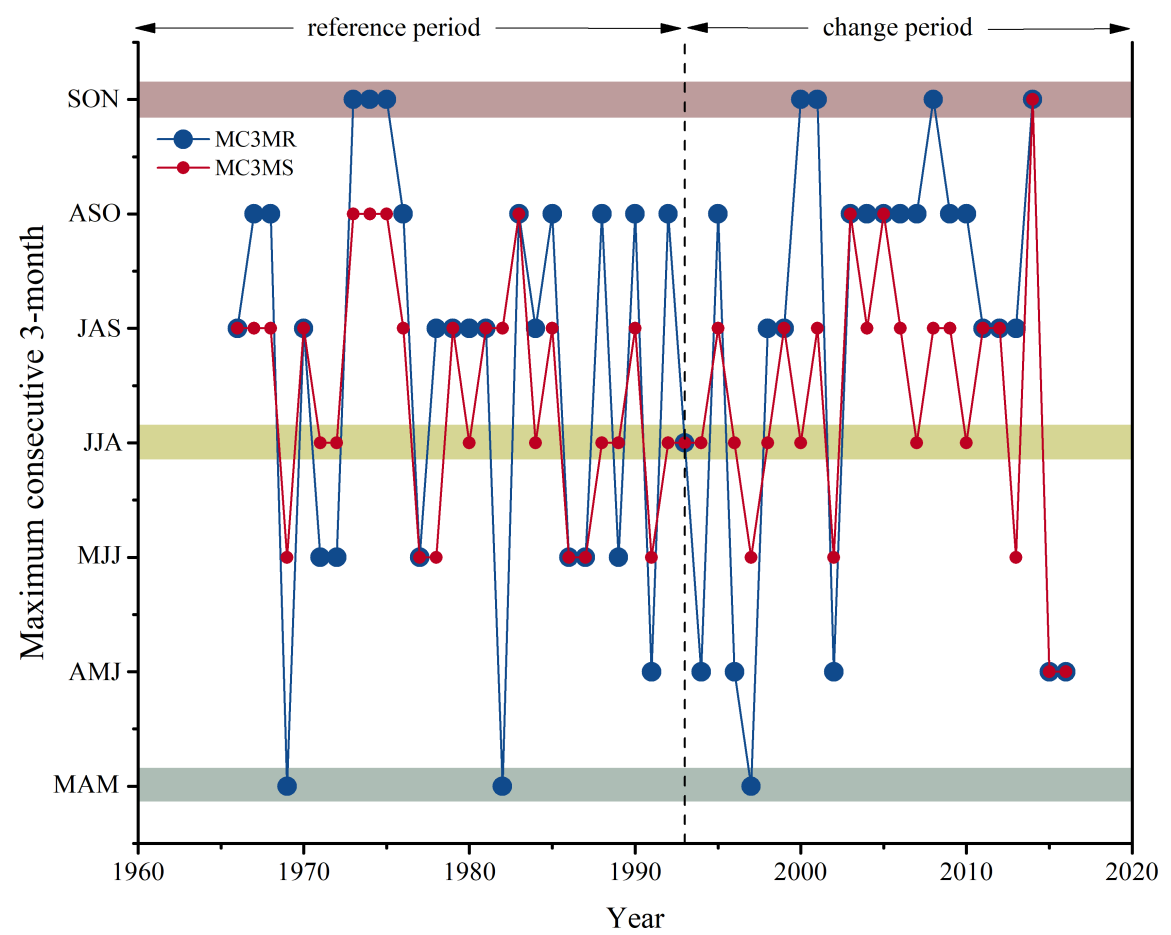



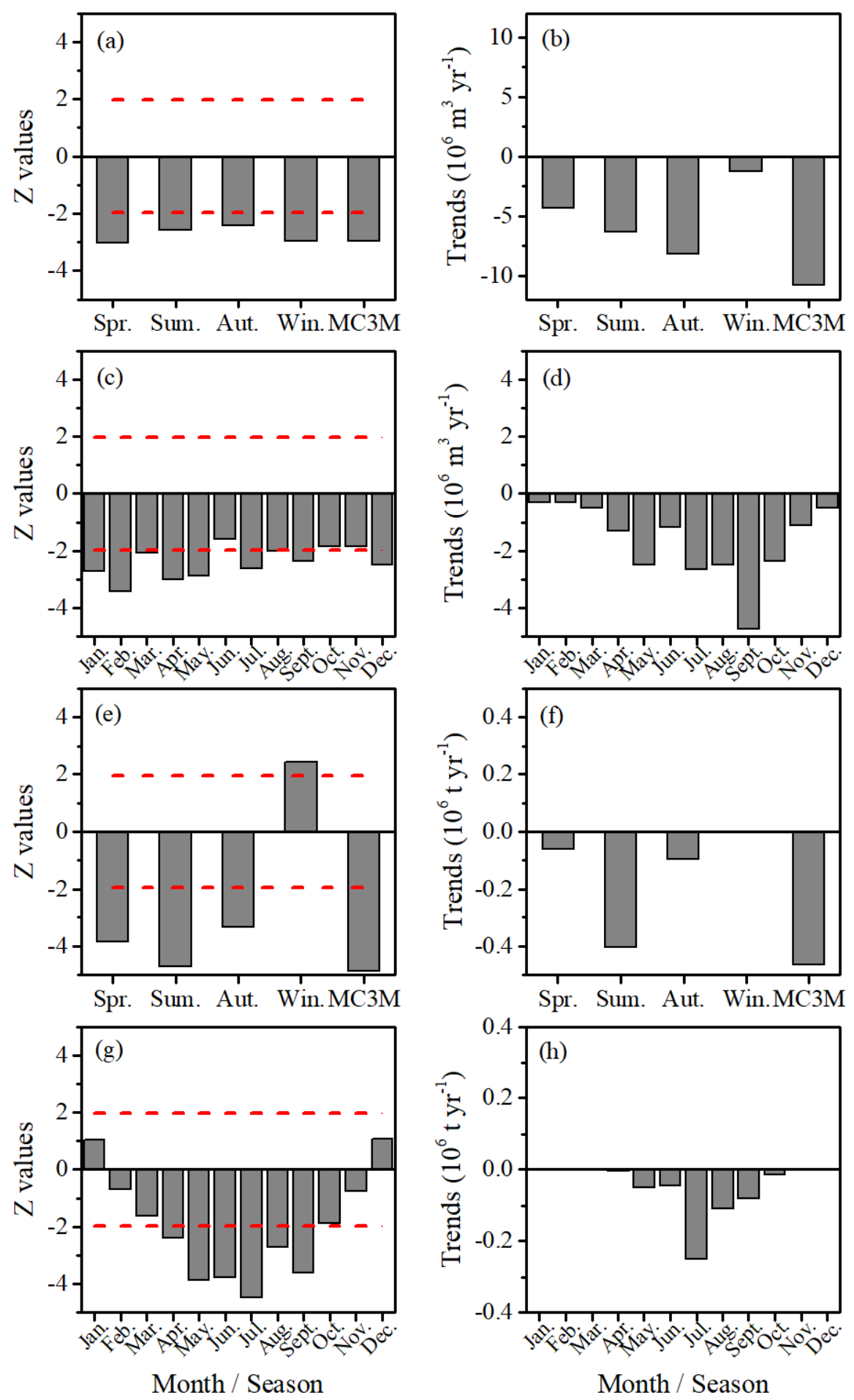

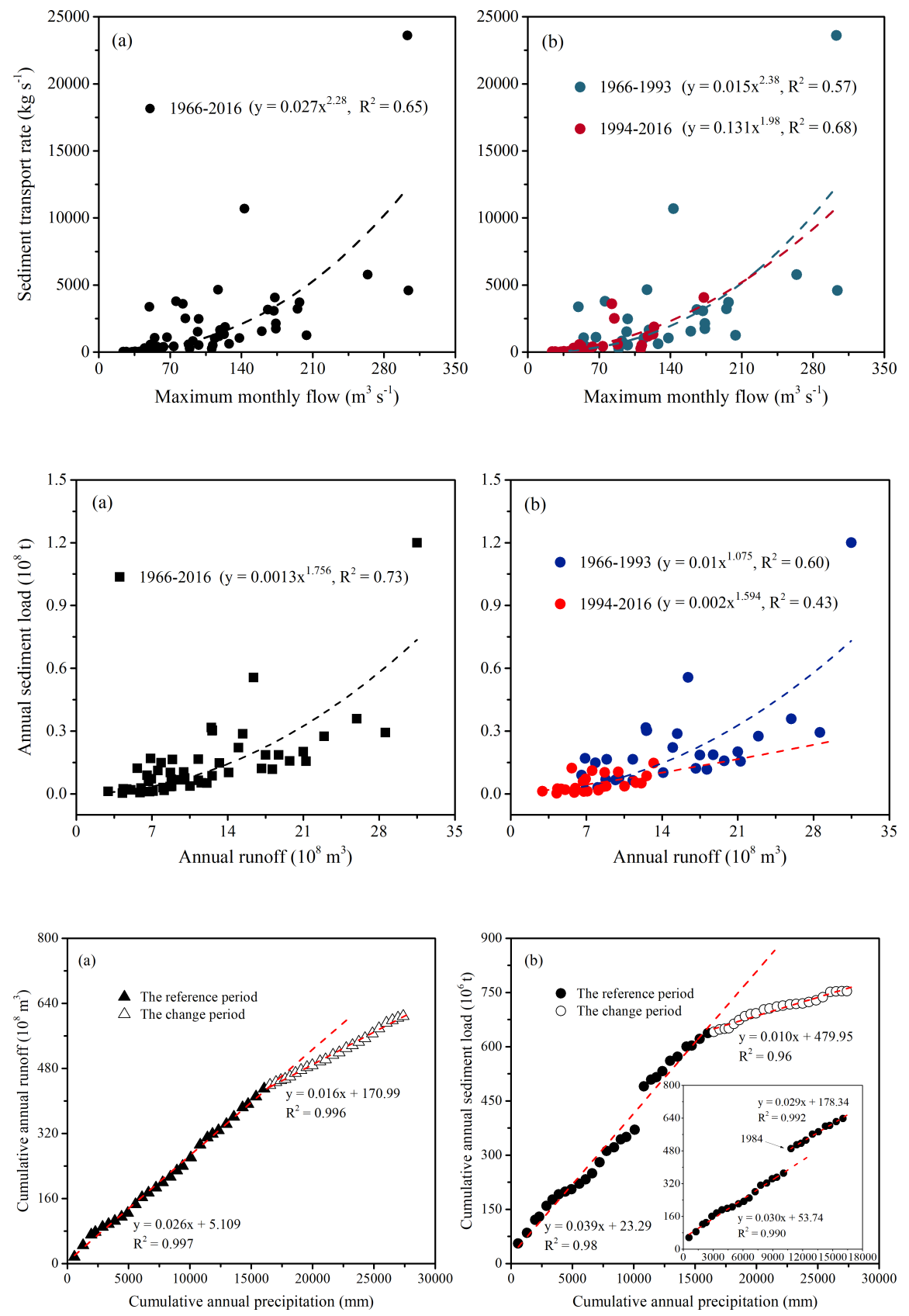

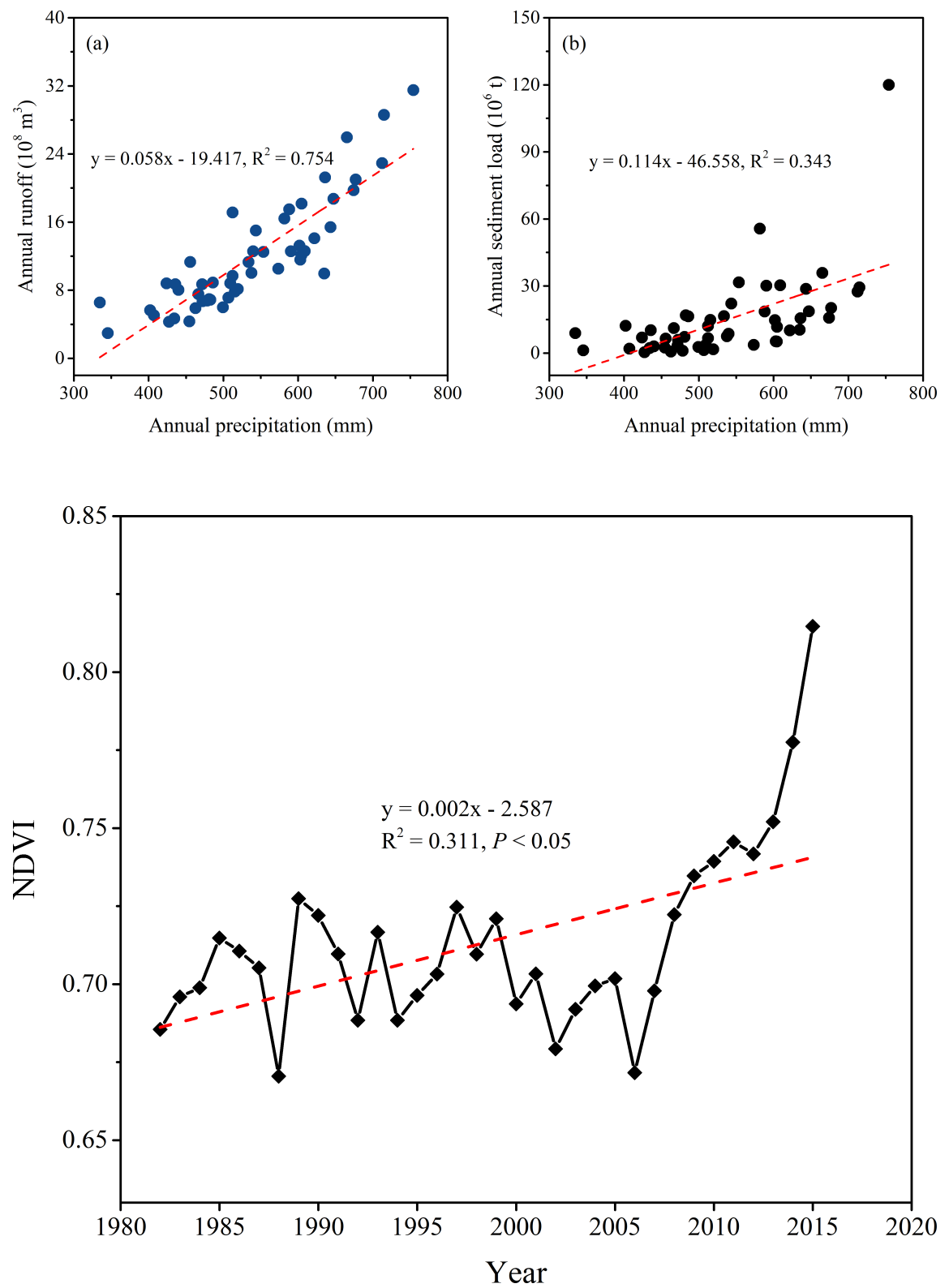